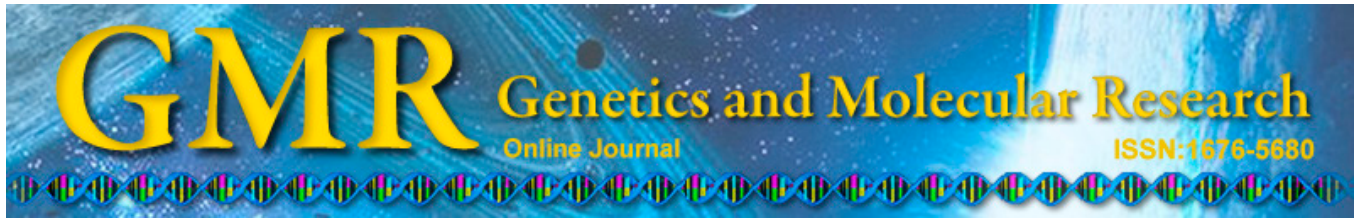

\title{
Phylogeography of pink pineapple mealybugs, Dysmicoccus brevipes (Cockerell) reveals the history of pineapple introduction and cultivation in China
}

\author{
Y.B. He, R.L. Zhan, G.M. Sun, J.B. Wu and Y.L. Zhao \\ Center of Pineapple Germplasm Innovation \& Utilization in Hainan Province, \\ South Subtropical Crops Research Institute, \\ Chinese Academy of Tropical Agricultural Sciences, Zhanjiang, China \\ Corresponding author: Y.B. He \\ E-mail: heyanbiao2013@163.com
}

Genet. Mol. Res. 14 (3): 9890-9897 (2015)

Received February 11, 2015

Accepted May 15, 2015

Published August 19, 2015

DOI http://dx.doi.org/10.4238/2015.August.19.23

ABSTRACT. The pink pineapple mealybug (PPM), Dysmicoccus
brevipes (Cockerell) (Hemiptera: Pseudococcidae), is a widespread
plant-sucking insect of considerable concern because it transmits the
pineapple mealybug wilt-associated virus. Its distribution is closely
linked with its host, the pineapple [Ananas comosus (L.) Merrill] because
of its wingless and parthenogenetic characteristics. To investigate the
history of $D$. brevipes introduction and the cultivation of pineapple in
China, samples of $D$. brevipes were collected from the main pineapple
production region in China, and from Thailand, and the mitochondrial
cytochrome c oxidase subunit I (COI) gene was analyzed. Homologous
sequences of $D$. brevipes COI from Brazil, Thailand, and Philippines
that are deposited in GenBank were compared. Phylogenetic analyses
suggest there are close genetic relationships between PPM populations
from Hawaii, Brazil, the Philippines, and from Thailand and China,
which probably originate from South America. It is suggested that 
most PPMs in China were introduced from South America by way of Southeast Asia, being accompanied by the pineapple seedling. Conversely, some PPMs represented by Haplotype-WN from Wanning of China, and Lampang of Thailand were found to differ greatly from populations in Hawaii, Brazil, the Philippines, Thailand, and China. It is possible that another route was used for the introduction and distribution of pineapple, or that pineapple might have originated in Southeast Asia.

Key words: Pink pineapple mealybug; Dysmicoccus brevipes (Cockerell); Haplotype; Introduction and cultivation; Pineapple

\section{INTRODUCTION}

The pineapple [Ananas comosus (L.) Merrill] is a tropical plant of high economic importance worldwide, especially in terms of its large area of cultivation, high yield, and excellent consumer market (Lacerda et al., 2009), and it is believed to be of South America origin. Suckers or ratoons pulled from the base of plants are the most typical planting materials used for commercial production in Southeast Asia, for the sake of faster growth and easier field management. It is therefore very important to dip the planting material into a fungicide/insecticide mixture several days before planting to prevent the introduction of pests to a new field.

Pink pineapple mealybug [PPM; Dysmicoccus brevipes (Cockerell)] is a major pest of pineapples in many countries, and is normally found on the base of the leaf and stem or on the roots of the plant. $D$. brevipes is ovoviviparous and reproduces parthenogenetically in most areas, including Hawaii and Jamaica (Beardsley, 1965; Seether et al., 2005). It is believed to be of New World origin (Seether, 2002).

Molecular methods have been used successfully to determine the invasion history of invasive taxa (Downie, 2002; Facon et al., 2003; Cognato et al., 2005). Phylogenetic analyses suggested that the source of $D$. brevipes in Hawaii was likely to be the mealybug lineage that lives predominantly in Brazil, Thailand, and the Philippines, according to the sequences of mitochondrial cytochrome c oxidase subunit I (COI) downloaded from GenBank. However, phylogenetic analyses also showed that PPMs from China are of different geographic origin to the samples from Hawaii (He et al., 2012).

Owing to the difficulty of finding a regular pattern of distribution from a large number of cultivated crop varieties, parthenogenetic and wingless pests on crops represent an alternative way to investigate historical routes of dispersal. To reveal the history of introduction of $D$. brevipes in the cultivation of pineapple in China, $D$. brevipes samples were collected from main pineapple production regions in China and Thailand and their mitochondrial COI sequences were analyzed. Furthermore, the homologous sequences of $D$. brevipes $C O I$ deposited in GenBank from Brazil, Thailand, and the Philippines were compared.

\section{MATERIAL AND METHODS}

\section{Processing of mealybugs}

PPMs from A. comosus were obtained from 14 counties across five provinces in China, and a sample of PPM from Hawaii, USA, was also included. In addition, Dysmicoccus 
neobrevipes Beardsley and Planococcus minor (Maskell) from China were used as outgroups in data analysis. Samples were collected in 2010-2014 (Table 1).

Table 1. Collection information of samples of Dysmicoccus brevipes and outgroup species.

\begin{tabular}{lll}
\hline Population name & Host species & Collection information \\
\hline Dysmicoccus brevipes & & \\
Hawaii & Ananas comosus & USA; Hawaii. Nov. 2010; Coll. D.M. Sether \\
Nanning & Ananas comosus & Nanning, China. May 2014; Coll. Y.B. He \\
Jinghong & Ananas comosus & Jinghong, China. Jul. 2010; Coll. Y.B. He \\
Xuwen & Ananas comosus & Xuwen, China. Oct. 2010; Coll. Y.B. He \\
Zhangzhou & Ananas comosus & Zhangzhou, China. Jul. 2010; Coll. Y.B. He \\
Leizhou & Ananas comosus & Leizhou, China. Oct. 2010; Coll. Y.B. He \\
Qionghai & Ananas comosus & Qionghai, China. Mar. 2014; Coll. Y.B. He \\
Wanning & Ananas comosus & Wanning, China. Mar. 2014; Coll. Y.B. He \\
Lampang 1 & Ananas comosus & Lampang, Thailand. Apr. 2014; Coll. Y.B. He \\
Lampang 2 & Ananas comosus & Lampang, Thailand. Apr. 2014; Coll. Y.B. He \\
Dysmicoccus neobrevipes & Agave sisalana & Zhanjiang, China. Sep. 2010; Coll. Y.B. He \\
Planococcus minor & Mangifera indica & Zhanjiang, China. Jul. 2010; Coll. Y.B. He \\
\hline
\end{tabular}

Live insects were carefully removed from the host plants and maintained without food for $24 \mathrm{~h}$ before being stored in $95 \%$ ethanol at $4^{\circ} \mathrm{C}$. Voucher samples are preserved at the South Subtropical Crops Research Institute, Chinese Academy of Tropical Agricultural Sciences.

Samples were rinsed with double distilled water and then air dried. All specimens were examined under a microscope for the presence of parasitoids. Total DNA was extracted from single parasitoid-free adult females using the TIANamp Genomic DNA kit (Tiangen Biotech, Beijing, China), following the manufacturer protocol.

\section{Template preparation and DNA manipulation}

A 649-bp region of the mitochondrial COI gene was amplified with the primers F: 5'-CCTTCAACTAATCATAAAAATATTAG-3' and R: 5'-TAAACTTCTGGATGTCCAAA AAATCA-3' (Park et al., 2010). PCR amplification was performed in $25-\mu \mathrm{L}$ reaction volumes with $3 \mu \mathrm{L}$ template DNA. The PCR mix contained $2.5 \mu \mathrm{L} 10 \mathrm{X}$ Taq reaction buffer (Promega, Madison, WI, USA), 0.5 U Taq DNA polymerase (Promega), $3.5 \mathrm{mM} \mathrm{MgCl}$, and $15 \mathrm{pM}$ of each primer. PCR conditions were as follows: $95^{\circ} \mathrm{C}$ for $3 \mathrm{~min}$, followed by 34 cycles of $95^{\circ} \mathrm{C}$ for $30 \mathrm{~s}, 55^{\circ} \mathrm{C}$ for $45 \mathrm{~s}, 72^{\circ} \mathrm{C}$ for $1.5 \mathrm{~min}$, and a final extension of $5 \mathrm{~min}$ at $72^{\circ} \mathrm{C}$.

Each PCR product $(5 \mu \mathrm{L})$ was run on a $1 \%$ agarose gel to determine the presence and size of amplified DNA. PCR products were sequenced in both forward and reverse directions. To achieve the whole ITS sequence, new primers were designed based on the intermediate sequence. Amplification products were purified and sequenced by Invitrogen Biotechnology (Shanghai, China) on both strands using PCR primers. Sequences of all COI haplotypes of PPM have been deposited in GenBank under accession No.: JN128960-JN128963; and those of D. neobrevipes and P. minor were JN128957 and JF965419, respectively. The homologous COI sequences of PPM from Brazil, Thailand, and the Philippines were obtained from GenBank with accession No. KJ530600-KJ530601, HM474137/HM474139, and HM474142-HM474144. 


\section{Data analysis}

Sequences were aligned using ClustalX (version 2.0) and unique haplotypes were identified with Arlequin (version 3.5). Descriptive statistics (number of variable sites, number of haplotypes, haplotype diversity, nucleotide diversity, average number of nucleotide differences between haplotypes) were generated using DNASP (version 5.0), and $\mathrm{F}_{\mathrm{ST}}$ was calculated using Arlequin version 3.5 (Excoffier et al., 2005).

The genealogical relationships based on 480-bp COI sequences of PPMs were studied by constructing a network based on the statistical parsimony method described by Templeton et al. (1992), using the software TCS 1.20 (Clement et al., 2000). A network can be more appropriate at depicting intraspecific gene genealogies than a bifurcating tree because of the potential for extinct ancestral nodes and multifurcating relationships (Posada and Crandall, 2001).

Phylogenetic analyses were performed by maximum parsimony (MP) and neighbor joining (NJ) analysis using PAUP* 4.10 (Swofford, 2003). Incongruence among data partitions was analyzed using a partition homogeneity test with 1000 replications as implemented in PAUP*. MP and NJ analyses used the heuristic search option with tree-bisectionreconnection branch swapping, collapsing zero-length branches, and equal weighting of all characters. MP bootstrap support was calculated using 1000 replicates.

\section{RESULTS}

D. brevipes was found to have a simple genetic structure, and 1-3 haplotypes of PPM were found in many populations (Table 2). According to the homologous sequences, TH1 from Thailand was the same as HI from Hawaii.

Table 2. Distribution frequencies of different haplotypes in geographical populations of Dysmicoccus brevipes.

\begin{tabular}{|c|c|c|c|c|c|c|}
\hline \multicolumn{2}{|c|}{ Samples } & \multirow[t]{2}{*}{ Number of samples per population } & \multicolumn{4}{|c|}{ Haplotypes } \\
\hline Country & Population name & & HI/TH1 & $\mathrm{CN} 1$ & $\mathrm{CN} 2 / \mathrm{TH} 2$ & $\mathrm{CN} 3 / \mathrm{TH} 3$ \\
\hline$\overline{\text { USA }}$ & Hawaii & 30 & 30 & & & \\
\hline \multirow[t]{7}{*}{ China } & Nanning & 30 & & 30 & & \\
\hline & Jinghong & 30 & & 30 & & \\
\hline & Xuwen & 30 & & 30 & & \\
\hline & Zhangzhou & 30 & & 24 & 6 & \\
\hline & Leizhou & 46 & & 30 & 12 & 4 \\
\hline & Qionghai & 54 & & & 48 & 6 \\
\hline & Wanning & 92 & & 25 & 25 & 42 \\
\hline \multirow[t]{3}{*}{ Thailand } & Lampang 1 & 30 & & & 30 & \\
\hline & Lampang 2 & 30 & & & 21 & 9 \\
\hline & HM474137/HM474139 & Unknown & Unknown & & & \\
\hline
\end{tabular}

PPMs from Thailand and China were of three haplotypes, of which two were identical and one differed. The presence of two shared haplotypes suggests that there is a close relationship between pineapple cultivation in Thailand and China.

Haplotypes of $D$. brevipes clustered into three major clades based on the COI sequences. The first clade consisted of CN1, PHI, and CN2/TH2, the second clade included BR1, BR2, and HI/TH1, and another clade from China and Thailand was CN3/TH3 (Figures 1 and 2). 


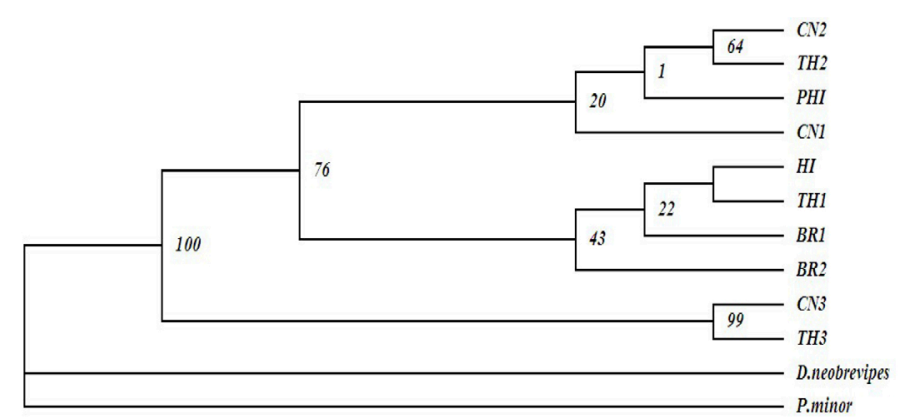

Figure 1. Maximal parsimonious tree of 10 haplotypes of Dysmicoccus brevipes. The PAUP 4.10 software was used for the analysis. Sequences of BR1, BR2, PHI, and TH1 were downloaded from GenBank. D. neobrevipes and P. minor were included as outgroups based on the 480-bp COI sequences.

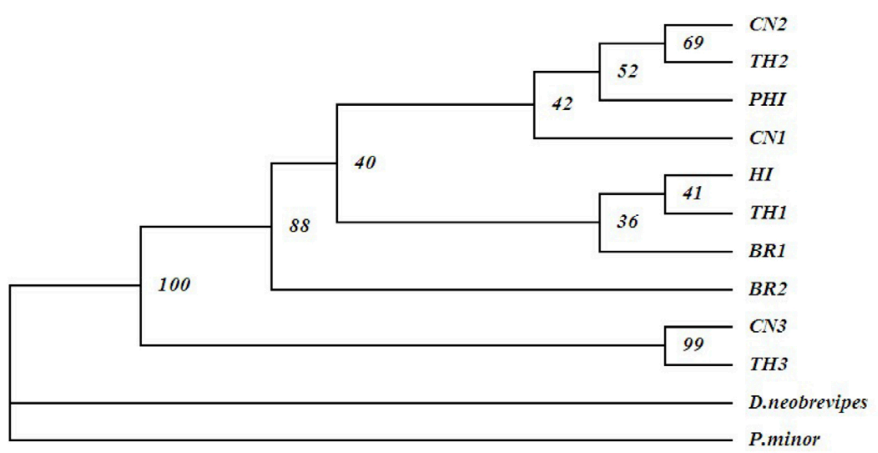

Figure 2. Neighbor joining tree of 10 haplotypes of Dysmicoccus brevipes. The PAUP 4.10 software was used for the analysis. Sequences of BR1, BR2, PHI, and TH1 were downloaded from GenBank. D. neobrevipes and P. minor were included as outgroups based on the 480-bp COI sequences.

The genetic distance between BR1, BR2, HI/TH1, CN1, PHI, and CN2/TH2 haplotypes was less than 0.006 , which is far lower than the genetic distance between $\mathrm{CN} 3 / \mathrm{TH} 3$. The genetic distance between $\mathrm{CN} 3 / \mathrm{TH} 3$ and other haplotypes ranged from 0.020 to 0.024 , which is far lower than their genetic distances from the related species, D. neobrevipes (Table 3).

Table 3. Genetic distances among different haplotypes of Dysmicoccus brevipes and Dysmicoccus neobrevipes.

\begin{tabular}{lccccccccccc}
\hline & CN3 & TH3 & CN2 & TH2 & PHI & CN1 & HI & TH1 & BR1 & D. neobrevipes & P. minor \\
\hline CN3 & - & & & & & & & & & & \\
TH3 & 0.000 & - & & & & & & & & & \\
CN2 & 0.022 & 0.022 & - & & & & & & & & \\
TH2 & 0.022 & 0.022 & 0.000 & - & & & & & & & \\
PHI & 0.020 & 0.02 & 0.002 & 0.002 & - & & & & & & \\
CN1 & 0.024 & 0.024 & 0.006 & 0.006 & 0.004 & - & & & & & \\
HI & 0.022 & 0.022 & 0.004 & 0.004 & 0.002 & 0.006 & - & & & & \\
TH1 & 0.022 & 0.022 & 0.004 & 0.004 & 0.002 & 0.006 & 0.000 & - & & \\
BR1 & 0.024 & 0.024 & 0.006 & 0.006 & 0.004 & 0.008 & 0.002 & 0.002 & - & & \\
BR2 & 0.020 & 0.020 & 0.006 & 0.006 & 0.004 & 0.008 & 0.002 & 0.002 & 0.004 & - & 0.115 \\
D. neobrevipes & 0.108 & 0.108 & 0.118 & 0.118 & 0.115 & 0.115 & 0.119 & 0.119 & 0.116 & 0.181 & \\
P. minor & 0.204 & 0.204 & 0.188 & 0.188 & 0.185 & 0.185 & 0.186 & 0.186 & 0.182 & 0.181 &
\end{tabular}

Sequences of BR1, BR2, PHI, and TH1 were downloaded from GenBank. 
This indicates that there are close genetic relationships among populations represented by the BR1, BR2, HI/TH1, CN1, PHI, and CN2/TH2 haplotypes. The population represented by $\mathrm{CN} 3 / \mathrm{TH} 3$ from China and Thailand diverged substantially from other populations.

\section{DISCUSSION}

Originating in the Amazon Basin in South America, A. comosus was introduced to Southeast Asia by the Portuguese in the 1550s (Institute of Fruit Tree Research, GDAAS, 1987). Pineapple was not cultivated commercially in large areas of south China until the late 19th and early 20th century (Zhao and Shen, 1987). Although there was not a explicit detailed scheme for that history, probably with the same as 'Smooth Cayenne' 300-400 years later (Figure 3). Distribution of the cultivar 'Smooth Cayenne' illustrates how the pineapple was introduced and the process of its cultivation around the world.



Figure 3. Distribution of the 'Smooth Cayenne' cultivar (Collins, 1951).

PPM is ovoviviparous and reproduces parthenogenetically in most areas as a wingless insect, and the female mealybug is normally distributed whilst hiding in the seedlings (He et al., 2012). Phylogenetic analyses suggest that there are close genetic relationships between PPM populations from Hawaii, Brazil, the Philippines, and from some resources from Thailand and China, and that they all probably originate from South America. It is thought that most PPMs in China were introduced from South America by way of Southeast Asia, being accompanied by the pineapple seedling. This is consistent with the history of the introduction 
of the pineapple and the process of its cultivation around the world.

It is difficult to speculate on the origin of a crop because of its frequent natural or artificial hybridization and the resulting complex genotypes. To a large extent, as a parasite, PPM is an appropriate alternate that can reveal the history of the introduction and cultivation of pineapple, because of its parthenogenesis and single genotype.

According to our result, some PPMs represented by Haplotype-WN from Wanning of China, and Lampang of Thailand differ greatly from populations in Hawaii, Brazil, the Philippines, and other samples from Thailand and China. PPMs from Southeast Asia have at least two origins, one is South America, and the other is Southeast Asia itself or elsewhere. In addition to South America, pineapples in Southeast Asia might also have another origin.

\section{Conflicts of interest}

The authors declare no conflict of interest

\section{ACKNOWLEDGMENTS}

Research supported in part by the Special Fund for Agri-Scientific Research in the Public Interest (\#201203021), the Natural Science Foundation of Hainan Province of China (\#313053), and the Youth Foundation of National Natural Science Foundation of China (\#31300348). We are grateful to Dr. F.C. Yang for helping to collect the insect samples from Thailand. Special thanks to Dr. D.M. Seether and Prof. J.S. Hu, for providing mealybug samples from Hawaii. The authors are also thankful to Prof. Y. Chen in Canada for his pertinent suggestions in English writing.

\section{REFERENCES}

Beardsley JW (1965). Notes on the Pineapple mealybug complex, with descriptions of two new species (Homoptera: Pseudococcidae). Proc. Hawaii Entomol. Soc. 19: 55-68.

Clement M, Posada D and Crandall KA (2000). TCS: a computer program to estimate gene genealogies. Mol. Ecol. 9: $1657-1660$

Cognato AI, Sun JH, Ancucho-Reyes MA and Owen DR (2005). Genetic variation and origin of red turpentine beetle (Dendroctonus valens LeConte) introduced to the People's Republic of China. Agric. Forest Entomol. 7: 87-94.

Collins JL (1951). Notes on the origin, history, and genetic nature of the Cayenne pineapple. Pac. Sci. 5: 3-17.

Downie DA (2002). Locating the sources of an invasive pest, grape phylloxera, using a mitochondrial DNA gene genealogy. Mol. Ecol. 11: 2013-2026.

Excoffier Laval LG and Schneider S (2005). Arlequin (version 3.0): an integrated software package for population genetics data analysis. Evol. Bioinform. Online 1: 47-50.

Facon B, Pointier JP, Glaubrecht M, Poux C, et al. (2003). A molecular phylogeography approach to biological invasions of the New World by parthenogenetic thiarid snails. Mol. Ecol. 12: 3027-3039.

He YB, Wan XW, Liu YH, Sun GM, et al. (2012). Mitochondrial COI from Dysmicoccus brevipes (Hemiptera: Pseudococcidae) suggests cryptic lineage and pinpoints the source of the introduction to China. Fla. Entomol. 95 : 183-191.

Institute of Fruit Tree Research, Guangdong Academy of Agricultural Sciences (1987). Pineapple and its Cultivation in China. China Light Industry Press, Beijing (In Chinese).

Lacerda JT, Carvalho RA and de Oliveira EF (2009). Cochonilha Dysmicoccus brevipes: a praga cosmopolita da abacaxicultura. Tecnol. Cienc. Agropec. João Pessoa 3: 15-21.

Park DS, Suh SJ, Oh HW and Hebert PDN (2010). Recovery of the mitochondrial COI barcode region in diverse Hexapoda through tRNA-based primers. BMC Genomics 11: 423.

Posada D and Crandall KA (2001). Intraspecifc gene genealogies: trees grafting into networks. Trends Ecol. Evol. 16: 37-45. 
Seether DM (2002). Pineapple mealybug wilt associated viruses: vectors, impacts, and dynamics. Doctoral thesis, University of Hawaii, Honolulu.

Seether DM, Melzer MJ, Busto J, Zee F, et al. (2005). Diversity and mealybug transmissibility of ampel viruses in pineapple. Plant Dis. 89: 450-457.

Swofford DL (2003). PAUP*: phylogenetic analysis using parsimony (*and other methods). Version 4. Sinauer, Sunderland.

Templeton AR, Crandall KA and Sing CF (1992). A cladistic analysis of phenotypic associations with haplotypes inferred from restriction endonuclease mapping and DNA sequence data. III. Cladogram estimation. Genetics 132: 619-633.

Zhao WZ and Shen XY (1987). Cultivation of pineapple. Chinese Agricultural Press, Beijing (In Chinese). 